\title{
More than 5 Mitoses per 50HPF
}

National Cancer Institute

\section{Source}

National Cancer Institute. More than 5 Mitoses per 50HPF. NCI Thesaurus. Code C54007.

A morphologic finding indicating the presence of more than five mitotic figures per fifty high power fields in a cellular infiltrate. 